\title{
Technology preferences among caregivers of children with hydrocephalus
}

\author{
Clinical article
}

\author{
Robert P. Naftel, M.D., Nicole A. Safiano, B.S., Michael I. Falola, M.D., M.P.H., \\ Chevis N. Shannon, M.B.A., Dr.P.H., John C. Wellons III, M.D., M.S.P.H., \\ AND JaMes M. JohnStOn JR., M.D.
}

Section of Pediatric Neurosurgery, Division of Neurosurgery, University of Alabama at Birmingham, Children's of Alabama, Birmingham, Alabama

\begin{abstract}
Object. The Internet and social media are powerful disseminators of medical information, providing new portals for patient care. The authors of this study evaluated current technology hardware, Internet, and social media use and their socioeconomic relationships among caregivers of children with hydrocephalus.

Methods. A written survey was completed in the neurosurgical clinics at the University of Alabama at Birmingham by 300 parents of children with shunted hydrocephalus between October 26, 2010, and July 26, 2011.

Results. Computer use (94.6\%), Internet use $(91.7 \%)$, smartphone use $(56.9 \%)$, and Internet research on hydrocephalus $(81.9 \%)$ were prevalent. However, for each of these four utilizations there was significantly lower access by caregivers of minority races $(\mathrm{p}=0.04,0.03,0.002$, and $<0.0001$, respectively), lower income $(\mathrm{p}=0.02$, $0.01,<0.0001$, and $<0.0001$, respectively), and lower level of education $(\mathrm{p}=0.001,0.002,<0.0001$, and 0.001 , respectively). Personal use of social media was prevalent (95.1\% of all Internet users) with use being more prevalent among less-educated than higher-educated caregivers $(\mathrm{p}=0.017)$. Hydrocephalus-related social media use $(59.5 \%$ of Internet users) was not associated with socioeconomic factors. For hydrocephalus education on the Internet, caregivers chose information websites such as Wikipedia or the Hydrocephalus Association as preferred platforms; these preferences were followed by use of social media websites. Facebook and YouTube were the preferred social media platforms for personal and hydrocephalus-related use. Parents indicate moderate skepticism about the trustworthiness of the Internet; only $21.7 \%$ always trust the online sources. Most parents (89.8\%) say that they would visit neurosurgeon-recommended websites. Of Internet-using caregivers, $28.6 \%$ use the Internet or social media to find hydrocephalus support groups, and $34.8 \%$ have used the Internet to communicate with other caregivers who have children with similar conditions.

Conclusions. Technology hardware, the Internet, and social media are widely used with some skepticism by parents of children with shunted hydrocephalus. Caregivers are interested in physician-recommended Internet resources. Socioeconomic factors including race, income, and level of education reveal a disparity in access to some of these resources, although all groups have relatively high use. Unlike typical technology use, social media use is breaking down the digital divide among ethnic and socioeconomic groups. (http://thejns.org/doi/abs/10.3171/2012.9.PEDS12208)
\end{abstract}

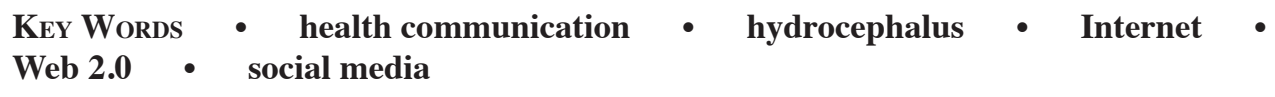

$\mathrm{P}$

ROVIDING care for children with hydrocephalus requires more than operative interventions. Caregivers (parents) must be empowered through education and social support. Caregiver education about hydrocephalus is considered essential in preventing significant morbidity and even mortality due to shunt failure. ${ }^{1,17}$ The Internet is an evolving tool in caregiver/patient education. ${ }^{2,8,9,14,19,25,26,31}$ In a bold statement in 1996,

Abbreviations used in this paper: GED = General Educational Development; HINTS = Health Information National Trends Survey; RSS = rich site summary (or really simple syndication).
Pareras and Martin-Rodriguez ${ }^{33}$ stated that "the Internet is dividing medical professionals, creating two kinds of people: those who take advantage of the benefits which the information era offers, and those who live in ignorance of these benefits." As recognized then, the Internet is a powerful disseminator of medical information and is recognized by neurosurgeons as an important adjunct to their practice..$^{23,27,31,33}$ This is especially relevant to hydrocephalus; as early as 2001, hydrocephalus possessed the

This article contains some figures that are displayed in color online but in black-and-white in the print edition. 
highest quality information on the Internet of all neurosurgery topics. ${ }^{7}$

Recently, the Internet evolved from Web 1.0, described as "static content," into Web 2.0, which supports "active user involvement" and is a "participatory web."14 Web 2.0 functions include social networking, blogging, applications, and multimedia sites such as YouTube. ${ }^{19}$ With the evolution of the Internet, physicians, caregivers, and patients are now interconnected in new, dynamic ways. Traditional Web 1.0 functionality provided a stream of information from one source to many consumers; Web 2.0 promotes equal sharing of information among all and creates a collective intelligence. ${ }^{14}$

By 2011, technology and Internet use were prevalent in the United States, with $74 \%$ of adults regularly using the Internet, ${ }^{8} 65 \%$ of Internet users accessing at least one social networking site, ${ }^{30}$ and $59 \%$ of all adults using the Internet to search for health information (80\% of all Internet users). ${ }^{8}$ This makes searching for health care-related information the third most common online activity. ${ }^{41}$ Internet research by caregivers about their child's condition shapes their interactions with physicians. ${ }^{40}$ Often, caregivers do not disclose their Internet searches to their physicians. ${ }^{2,38}$ While physicians are the preferred source of information, $, 13,22,35,40$ in reality, caregivers turn to the Internet for answers first, especially for rare and chronic conditions..$^{9,13}$

While Internet use is becoming nearly universal, the Pew Internet and American Life Project, ${ }^{8,11,18,36}$ Health Information National Trends Survey (HINTS), ${ }^{22,26,28}$ and disease-specific studies $2,6,20,34,37,39$ have found that socioeconomic disparities create a digital divide between patient populations. Interestingly, use of social media is reported to permeate all race, economic, and educational strata. ${ }^{5,12,30}$ As the Internet and social media become more intertwined with patient care, physicians must understand how caregivers use the Internet to enhance their health care experience and recognize any socioeconomic disparities.

\section{Methods}

\section{Patient Population and Data Collection}

Following institutional review board approval, a prospective survey study on Internet and technology use among caregivers of patients with shunted hydrocephalus was conducted through the pediatric neurosurgical clinics at Children's of Alabama from October 26, 2010, through July 26, 2011. The term "caregiver" is used to refer to all parents or other legal guardians. For the purposes of the study, the term "e-caregiver" is defined as a caregiver who uses the Internet. Children's of Alabama serves a shunted hydrocephalus population of 3000 patients who have received shunts for hydrocephalus treatment. According to a public health survey specialist, a survey of $10 \%$ of this population was estimated to be representative of the group. Therefore, 300 caregivers were surveyed over the study period. Participants were recruited if the following eligibility criteria were met: 1) previously diagnosed shunted hydrocephalus and 2) pres- ence of a parent or legal guardian in clinic who could speak and read English.

Caregivers were approached regarding participation during routine neurosurgery follow-up visits. After receiving instruction from the study team member, the caregiver completed the written survey. The survey was completed in a written rather than electronic format to eliminate any technology education bias.

\section{Survey Design}

The Internet Usage Survey was designed by the study team, which included an attending neurosurgeon, resident, research assistant, and public health specialist with expertise in survey design. The survey contained 29 questions utilizing Likert scales, ${ }^{29}$ multiple choice, and free text response styles. The mean response rate to the individual questions was $96.0 \%$ (range $83.6 \%-100 \%$ ) with one question response rate as an outlier at $65.4 \%$. The questions were categorized under "Computer Usage," "Internet Usage," "Hydrocephalus and Shunts," "Social Networking, Blogs, and YouTube," "Hydrocephalus Support Groups," and "Personal Information." If the participants answered "no" to using the Internet, then they were asked to skip to the "Personal Information" section. Although the survey was administered in a written format, it was designed using SurveyMonkey (http://www.surveymonkey.com/), a website that allows users to design a survey, collect responses, and analyze the results.

After a pilot survey was completed by 34 participants, we determined that 6 questions were unclear and those were reformatted. After reformatting of the survey, an additional 266 caregivers were surveyed. The 6 questions that were unclear were eliminated and not analyzed. Therefore, for the 23 questions that were not reformatted, the total number of analyzed surveys was 300 . For the 6 questions that were reformatted, the number analyzed was 266.

Under the personal information section, participants were asked for information regarding their child's hydrocephalus history as well as household socioeconomic information. Using ZIP codes and 2000 Census Data (http:// www.census.gov), geographic location was defined as urban or rural. Additional patient demographics determined by chart review were age, gender, race, insurance status, and etiology of hydrocephalus. Categories of hydrocephalus etiology defined in protocols from the Hydrocephalus Clinical Research Network were used.

For the purposes of this study, social media users were defined as participants who used at least one form of social media and "strongly liked," "liked," or were "neutral" about it. Participants who did not report using any form of social media or only "disliked" or "strongly disliked" social media were not considered users of social media. Specific social media were chosen for questions with the intention of including the most frequently used media in the general population (Table 1).

\section{Statistical Analysis}

The data from the SurveyMonkey database were imported into SAS Statistical Software (SAS Institute, Inc.) 
TABLE 1: Definitions of specific social media analyzed in this study

\begin{tabular}{|c|c|c|c|}
\hline Social Media & Founded & Description or Mission Statement* & Web Address \\
\hline blogs & late $1990 \mathrm{~s}$ & $\begin{array}{l}\text { "a personal journal published on the World Wide Web consisting of discrete entries ("posts") } \\
\text {... Blogs are usually the work of a single individual, occasionally of a small group, and } \\
\text { often are themed on a single subject." } \dagger\end{array}$ & not applicable \\
\hline Myspace & 2003 & $\begin{array}{l}\text { "a leading social entertainment destination powered by the passions of fans. Aimed at a Gen } \\
\text { Y audience, Myspace drives social interaction by providing a highly personalized experi- } \\
\text { ence around entertainment and connecting people to the music, celebrities, TV, movies, } \\
\text { and games that they love." }\end{array}$ & http://www.myspace.com \\
\hline Facebook & 2004 & $\begin{array}{l}\text { "to give people the power to share and make the world more open and connected." "Millions } \\
\text { of people use Facebook everyday to keep up with friends, upload an unlimited number of } \\
\text { photos, share links and videos, and learn more about the people they meet." }\end{array}$ & https://www.facebook.com \\
\hline YouTube & 2005 & $\begin{array}{l}\text { "allows billions of people to discover, watch and share originally-created videos. YouTube } \\
\text { provides a forum for people to connect, inform, and inspire others across the globe and } \\
\text { acts as a distribution platform for original content creators and advertisers large and small." }\end{array}$ & http://www.youtube.com \\
\hline Twitter & 2006 & $\begin{array}{l}\text { "To instantly connect people everywhere to what's most important to them." "Twitter is a real- } \\
\text { time information network that connects you to the latest stories, ideas, opinions and news } \\
\text { about what you find interesting." }\end{array}$ & http://twitter.com \\
\hline
\end{tabular}

* Quotations are from the mission statement of the site.

† Because blogs are not a specific website, the description is taken from Wikipedia (http://www.wikipedia.org).

for further management and analysis. The socioeconomic characteristics of the caregivers and the children with shunted hydrocephalus were summarized using means for continuous variables and percentages for categorical variables. The differences among the categorical variables were tested using the chi-square test or the Fisher exact test, and the differences between the continuous variables were tested with the Student t-test. Statistical significance was defined as $\mathrm{p}<0.05$.

\section{Results}

\section{Caregiver and Patient Characteristics}

Over the 9-month prospective study period, 300 caregivers of children with shunted hydrocephalus completed an Internet Usage Survey in the neurosurgical clinics of 5 surgeons and a multidisciplinary spina bifida clinic. Demographic characteristics of the caregivers are presented in Table 2 . The mean age was $36.7 \pm 10.4$ years. Education levels were diverse and well distributed; $50.2 \%$ of the caregivers had completed a technical diploma, bachelor's degree, or higher level of education, and only $10.2 \%$ had failed to complete high school or a GED. Household yearly income was also evenly distributed, with the majority $(84.3 \%)$ above the poverty line of $\$ 10,800$. However, most households $(63.6 \%)$ made $\$ 50,000$ or less per year. Two adults occupied the majority of households (66.3\%), while $18.7 \%$ were single-parent households. Most families $(63.3 \%)$ lived in a rural setting as defined by census definitions.

Patient demographic characteristics are presented in Table 3. Patients were mostly Caucasian (65.7\%) and African American (32.3\%) with very few Hispanic or Asian patients (English-language speaking was required for completion of the survey). Insurance status was classified as either government (Medicaid or Medicare) or private,
TABLE 2: Characteristics of 300 caregivers of children with shunted hydrocephalus*

\begin{tabular}{lc}
\hline \multicolumn{1}{c}{ Characteristic } & Value \\
\hline mean age of caregiver in yrs & $36.7 \pm 10.4$ \\
highest level of education of caregiver $(n=293)$ & \\
$\quad$ did not complete high school or GED & $30(10.2)$ \\
high school or GED & $116(39.6)$ \\
technical degree or 2-yr college & $67(22.9)$ \\
bachelor's degree & $48(16.4)$ \\
graduate degree & $32(10.9)$ \\
household yearly income in $\$(n=280)$ & \\
$0-10,800$ & $44(15.7)$ \\
$10,801-50,000$ & $134(47.9)$ \\
$50,001-75,000$ & $44(15.7)$ \\
$75,001-100,000$ & $32(11.4)$ \\
$>100,000$ & $26(9.3)$ \\
no. of adults in household $(n=294)$ & \\
1 & $55(18.7)$ \\
2 & $195(66.3)$ \\
3 & $25(8.5)$ \\
4 & $13(4.4)$ \\
5 or more & $6(2.0)$ \\
urban & \\
rural & $106(36.7)$ \\
\hline
\end{tabular}

* Values indicate numbers of caregivers (\%) unless otherwise indicated. Numbers of respondents are indicated for each category. Mean values are given \pm SD. 
TABLE 3: Characteristics of 300 children with shunted hydrocephalus*

\begin{tabular}{|c|c|}
\hline Characteristic & Value \\
\hline mean age (yrs) & $8.2 \pm 5.8$ \\
\hline \multicolumn{2}{|l|}{$\operatorname{sex}(n=300)$} \\
\hline male & $166(55.3)$ \\
\hline female & $134(44.7)$ \\
\hline \multicolumn{2}{|l|}{ race $(n=297)$} \\
\hline Caucasian & $195(65.7)$ \\
\hline African American & $96(32.3)$ \\
\hline Hispanic & $3(1.0)$ \\
\hline Asian & $2(0.7)$ \\
\hline other & $1(0.3)$ \\
\hline \multicolumn{2}{|l|}{ insurance status $(n=300)$} \\
\hline government & $168(56.0)$ \\
\hline private & $132(44.0)$ \\
\hline \multicolumn{2}{|l|}{ etiology of hydrocephalus $(n=300)$} \\
\hline myelomeningocele & $82(27.3)$ \\
\hline PHHP & $81(27.0)$ \\
\hline other congenital & $31(10.3)$ \\
\hline communicating congenital & $25(8.3)$ \\
\hline status post-head injury & $14(4.7)$ \\
\hline aqueductal stenosis & $14(4.7)$ \\
\hline posterior fossa cyst or Dandy-Walker malformation & $12(4.0)$ \\
\hline spontaneous ICH, IVH, or SAH & $11(3.7)$ \\
\hline other intracranial cyst & $9(3.0)$ \\
\hline infection & $9(3.0)$ \\
\hline pseudotumor cerebri & $4(1.3)$ \\
\hline posterior fossa tumor & $4(1.3)$ \\
\hline encephalocele & $3(1.0)$ \\
\hline supratentorial tumor & $1(0.3)$ \\
\hline \multicolumn{2}{|l|}{ no. of shunt surgeries $(n=294)$} \\
\hline $0-2$ & $170(57.8)$ \\
\hline $3-6$ & $82(27.9)$ \\
\hline $7-9$ & $14(4.8)$ \\
\hline 10 or more & $28(9.5)$ \\
\hline mean no. of yrs w/ shunt & $7.3 \pm 5.7$ \\
\hline
\end{tabular}

* Values indicate numbers of patients (\%) unless otherwise indicated. Numbers of respondents are indicated for each category. Mean values are given $\pm \mathrm{SD}$. Abbreviations: $\mathrm{ICH}=$ intracranial hemorrhage; IVH = intraventricular hemorrhage; $\mathrm{PHHP}=$ posthemorrhagic hydrocephalus of prematurity; $\mathrm{SAH}=$ subarachnoid hemorrhage.

with the majority having government insurance (56.0\%). Ages of the children ranged from 0 to 21 years with a mean of just over 8 years. The most common etiologies of hydrocephalus were myelomeningocele $(27.7 \%)$ and posthemorrhagic hydrocephalus of prematurity (27.4\%). Children had had shunts in place for hydrocephalus for an average of 7 years, and most children had had few device revisions; $57.8 \%$ had undergone $0-2$ revisions and only $14.3 \%$ had undergone more than 6 shunt revisions.
Technology Hardware, Internet, and Social Media Personal Use

The majority of caregivers owned computers, digital music players, and smartphones. Most (94.6\%) used computers, and $86.7 \%$ had a computer at home. More caregivers had access to an iPod or digital music player (70.3\%) than a smartphone $(56.9 \%)$.

The majority $(91.7 \%)$ of caregivers surveyed used the Internet (e-caregivers), and $90.3 \%$ of e-caregivers had access at home. Most e-caregivers $(62.8 \%)$ used the Internet 7 days a week, and $83.0 \%$ used the Internet most days of the week (4 or more days). E-caregivers indicated that they most frequently accessed the Internet on their home computer, followed by their smartphone. Work and public (library) computers were used less frequently.

Most e-caregivers (95.1\%) accessed at least one form of social media. Of the social media sites, Facebook (76.5\% "like" or "strongly like") and YouTube (75.2\% "like" or "strongly like") were the most commonly used. Blogs, Myspace, and Twitter were less commonly used. Myspace initiated the most negative responses (18.4\% "dislike" or "strongly dislike"), and most e-caregivers $(51.3 \%)$ had never used Twitter.

There was socioeconomic disparity in computer, smartphone, and Internet use associated with race, income, and education. More Caucasians than African Americans used computers $(97.4 \%$ vs $88.5 \%$, respectively; $\mathrm{p}=0.04)$, smartphones $(63.1 \%$ vs $46.3 \%$, respectively; $\mathrm{p}=0.002)$, and the Internet $(94.9 \%$ vs $85.4 \%$, respectively; $\mathrm{p}=0.03)$. As household yearly income increased, computer $(\mathrm{p}=0.02)$, smartphone $(\mathrm{p}<0.0001)$, and Internet $(\mathrm{p}=0.01)$ use also increased. For example, all caregivers earning more than $\$ 75,000$ annually used the Internet in comparison with only $84.1 \%$ of those whose earnings were below the poverty line $(p=0.01)$. Lastly, higher levels of educational achievement correlated with higher levels of computer $(\mathrm{p}=0.001)$, smartphone $(\mathrm{p}<0.0001)$, and Internet use $(\mathrm{p}=0.002)$. For example, $79.2 \%$ of caregivers who had completed a bachelor's degree owned a smartphone compared with only $30.0 \%$ of those who had not completed high school or the GED, and all caregivers who completed a bachelor's degree used the Internet compared with only $73.3 \%$ who had not completed high school or an equivalency program. There was no association of computer, smartphone, or Internet use with geographic location (urban vs rural), age of the caregiver, or number of adults in the household (single parent).

While social media use was prevalent among all socioeconomic groups, it only correlated with level of education. Interestingly, social media use was nearly universal among those with high school level and below education (99.1\%) compared with more highly educated e-caregivers $(92.1 \%)$ ( $p=0.017)$. Among e-caregivers, social media use was not associated with race, income, geographic location (urban vs rural), age of the parent, or number of adults in the household (single parent).

\section{Hydrocephalus-Related Internet and Social Media Use}

The majority $(81.9 \%)$ of e-caregivers $(75.3 \%$ of all caregivers) reported searching for hydrocephalus-related 
information online, and, although nearly all e-caregivers used social media for personal purposes, only $59.5 \%$ used social media for hydrocephalus-related purposes. Most e-caregivers $(85.8 \%)$ found the Internet somewhat or very helpful in learning about hydrocephalus (Fig. 1A). Of note, $89.8 \%$ of e-caregivers expressed interest in guidance from their neurosurgeon about which online resources to use (Fig. 1B). Only $9.4 \%$ responded that they would be very unlikely to use these resources. E-caregivers indicated slight skepticism about the trustworthiness of Internet information with $57.8 \%$ responding that they only sometimes trusted hydrocephalus information found on the Internet (Fig. 1C). However, a smaller proportion $(21.7 \%)$ always trusted Internet information.

When asked about specific social media, e-caregivers most commonly responded that they did not use social media for hydrocephalus-related purposes or that they were neutral about each platform. The platforms that were preferred were the same as for personal use. Facebook (29.4\% "like" or "strongly like") and YouTube
(29.5\% "like" or "strongly like") were favored, followed by blogs (19.9\% "like" or "strongly like"). Myspace and Twitter were not preferred for this purpose; nearly half of the respondents had never used these sites for this purpose (Fig. 2).

Similar to personal technology use, disparities of race, income, and education were found for hydrocephalus-related Internet use (Fig. 3). More Caucasian than African American e-caregivers used the Internet to obtain hydrocephalus information $(89.8 \%$ vs $63.4 \%$, respectively; $\mathrm{p}<$ $0.0001)$. Internet use increased as income increased ( $\mathrm{p}<$ 0.0001 ). Internet use for hydrocephalus information sequentially increased as each higher level of education was attained $(\mathrm{p}=0.001)$. There was no association with geographic location (urban vs rural), age of the parent, etiology of hydrocephalus, number of shunt revisions, or number of years that the child had been treated with a shunt.

E-caregivers who were more experienced with shunt failure were less likely to use social media for hydrocephalus-related purposes: $46.9 \%$ of e-caregivers with children
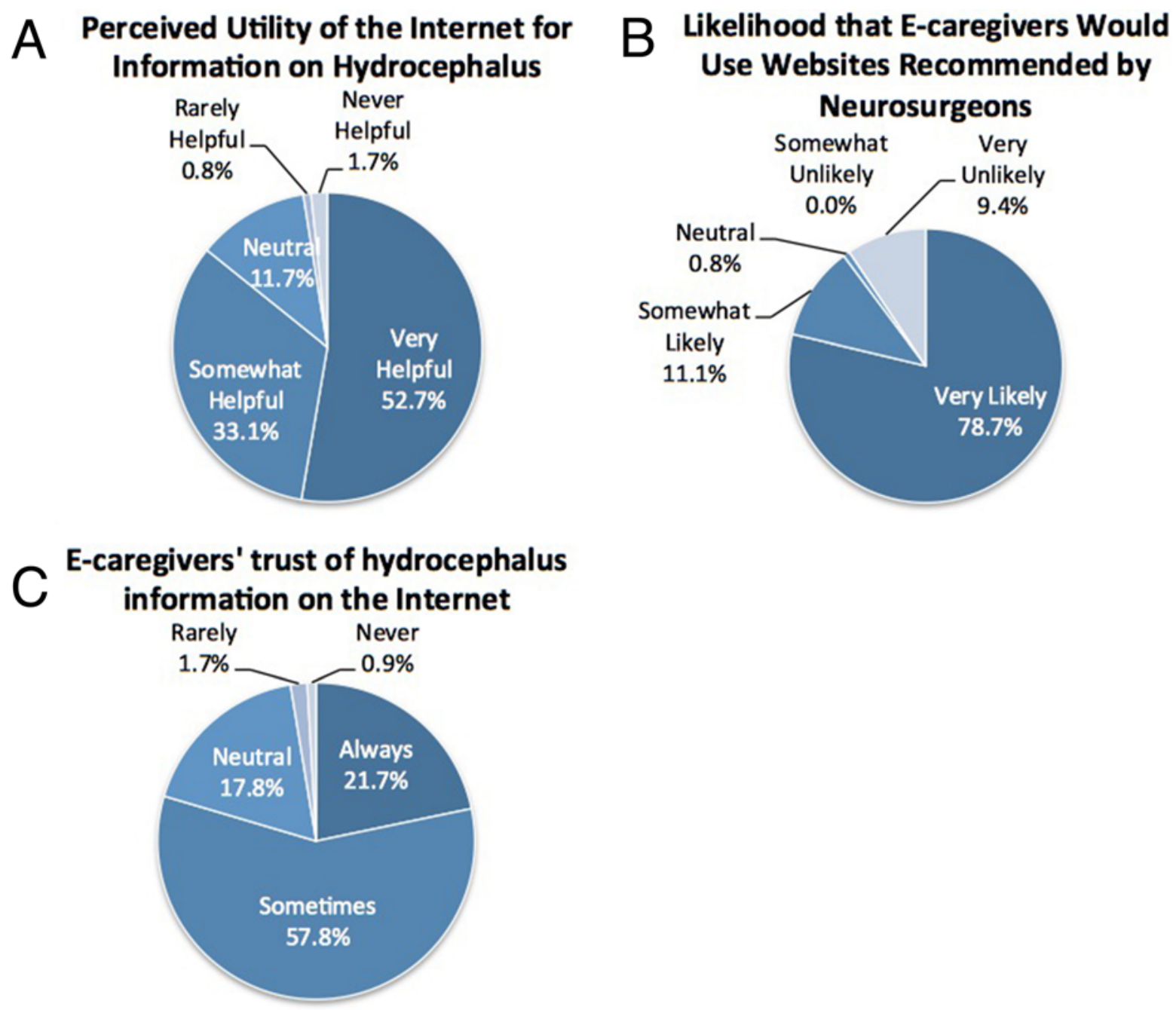

Fig. 1. A: E-caregivers responded that the Internet is generally helpful for finding information on hydrocephalus and shunts. B: Ninety percent of e-caregivers responded that they would be somewhat or very likely to use neurosurgeon-recommended websites. Only $9.4 \%$ responded that they would be very unlikely to visit these sites. C: E-caregivers expressed slight skepticism about the trustworthiness of hydrocephalus and shunt information found on the Internet. 


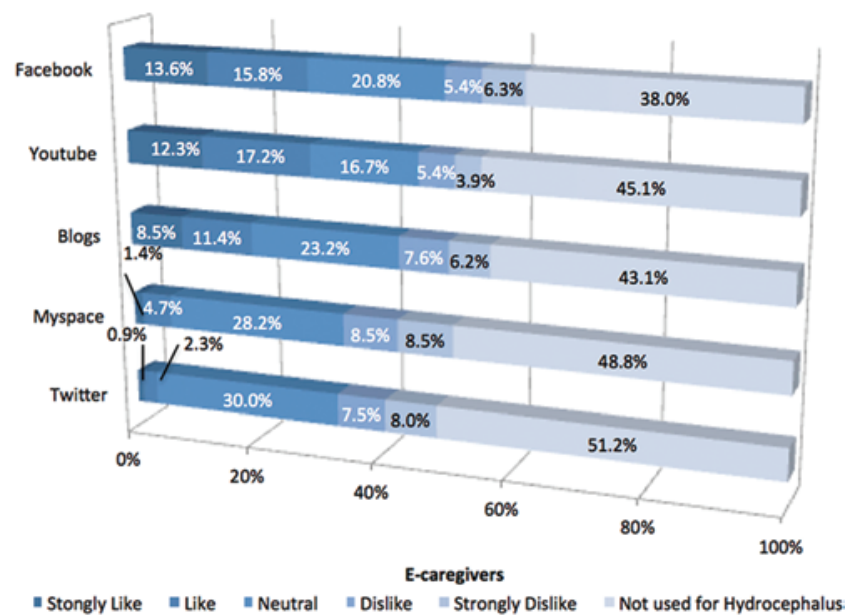

FIG. 2. A comparison of social media preferences for hydrocephalus-related use among caregivers of children with hydrocephalus. Facebook and YouTube were preferred, although not to the same degree as for personal use. Most commonly, caregivers had not used these specific social media for this purpose.

experiencing 7 or more shunt revisions compared with $61.1 \%$ of those experiencing fewer than 7 shunt revisions used social media for hydrocephalus-related purposes $(\mathrm{p}=$ 0.016). (While the stratification of shunt failure experience may seem arbitrary, this same stratification has been used in previous studies. ${ }^{24,32}$ ) Social media use for hydrocephalus-related purposes was not associated with race, income, geographic location (urban vs rural), age of the parent, number of adults in household (single parent), number of years with shunt, or etiology of hydrocephalus.

\section{Internet Platforms and Topics of Interest}

When e-caregivers were asked about their preferred Internet formats, information sites such as the Hydrocephalus Association website (http://www.hydroassoc. org) or Wikipedia were the most preferred platforms (Fig. 4). After information sites, e-caregivers preferred social media sites such as Facebook or Myspace and YouTube videos for learning about hydrocephalus. E-caregivers expressed decreasing preference for blogs, RSS, and podcasts, generally conveying apathy toward these media.

The majority $(78.0 \%)$ of e-caregivers were somewhat

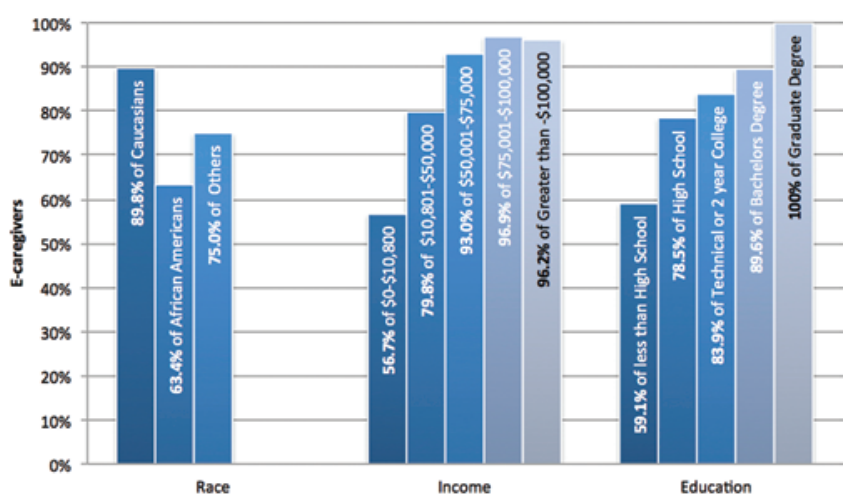

Fig. 3. A comparison of hydrocephalus-related Internet use by socioeconomic strata among e-caregivers. Caucasian race, higher income, and higher levels of education correlate with increased use.

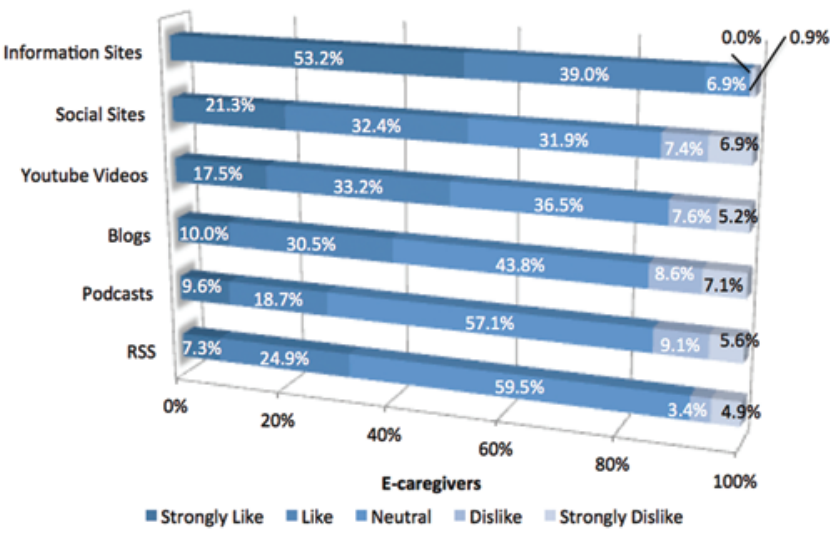

FIG. 4. When going online for hydrocephalus information, e-caregivers preferred information sites, social sites, and YouTube videos. Decreasing preference was seen for blogs, podcasts, and RSS.

or very likely to watch educational videos on YouTube. Only $7.6 \%$ responded that they would be very unlikely to watch YouTube videos. Podcasts were preferred less than YouTube videos. Only $23.5 \%$ of e-caregivers had ever downloaded a podcast; however, $55.1 \%$ said they would be somewhat or very likely to download one about hydrocephalus or shunts, and $19 \%$ responded that they would be very unlikely to download a podcast.

While information sites like the Hydrocephalus Association website and Wikipedia were the most preferred media platforms, e-caregiver preference for them decreased as level of education increased; only $81.8 \%$ of graduate degree educated e-caregivers liked these sites compared with $88.9 \%$ of people who never graduated from high school or attained a GED ( $p=0.004)$. Additionally, preference for social media sites was associated with non-Caucasian races $(67.2 \%$ non-Caucasian vs $48.4 \%$ Caucasian, $\mathrm{p}=0.04)$, lower income $(\mathrm{p}=0.004)$, and use of government insurance rather than private insurance $(\mathrm{p}=0.005)$.

E-caregivers were asked about which hydrocephalus or shunt topics were most important to them (Fig. 5). They gave highest priority to information about shunt failure, followed closely by general information about hydrocephalus and shunts. E-caregivers also expressed interest in new therapies, with $50.5 \%$ of respondents describing online search for support groups as somewhat or very important. There was no association between topics of importance and etiology of hydrocephalus, number of shunt revisions, or number of years the child had been treated with a shunt.

\section{Support Groups}

The Internet was used by $28.6 \%$ of e-caregivers to find support groups, and $34.8 \%$ have used the Internet to communicate with other caregivers who have children with similar conditions. E-caregivers below the poverty line were significantly less likely to use the Internet for support groups $(8.3 \%$ below poverty line vs $32.0 \%$ above, $\mathrm{p}=0.04)$. Households with two adults used the Internet to find support groups significantly more frequently (33.3\%) than households with single parents $(18.4 \%)$ or three or more adults $(13.6 \%, \mathrm{p}=0.03)$. Use of the Internet for 


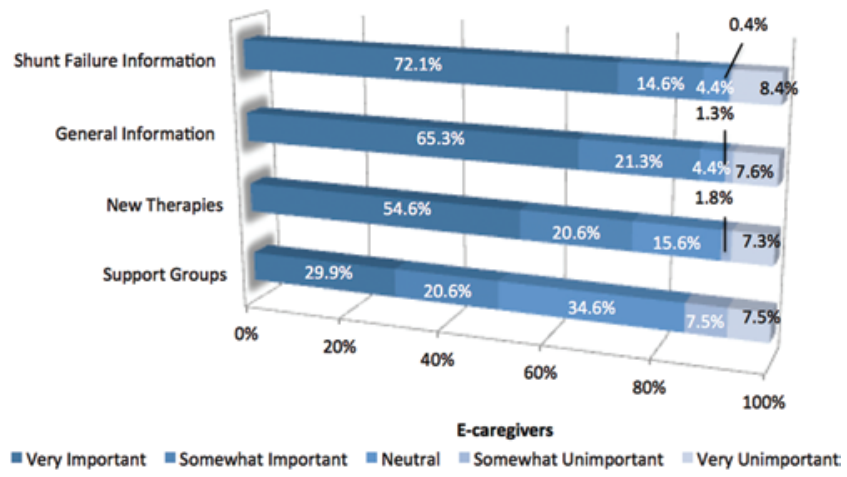

FIG. 5. E-caregivers expressed interest in using the Internet to learn about shunt failure, general information about hydrocephalus, and new therapies. A large number of e-caregivers (50.5\%) found the Internet to be very or somewhat important for accessing support groups.

support groups was not associated with race, education, geographic location (urban vs rural), age of the parent, number of years with shunt, number of shunt revisions, or etiology of hydrocephalus.

In general no social media platform was felt to be exceptional in providing support (Fig. 6). Facebook, YouTube, and blogs were the most preferred and Twitter and Myspace were least preferred. Preference of specific social media for support groups was not associated with any socioeconomic factors.

\section{Discussion}

\section{Technology and Internet Use}

Access to technology hardware, the Internet, and social media were prevalent among caregivers of children with hydrocephalus. These caregivers most commonly accessed the Internet at home or on their smartphone, doing so most days of the week. Hydrocephalus caregivers reported high degrees of Internet $(91.7 \%)$ and smartphone $(56.9 \%)$ use compared with the reported adult rates $(74 \%$ and $35 \%$, respectively). ${ }^{8}$ Additionally, these hydrocephalus caregivers had high rates of hydrocephalus-related

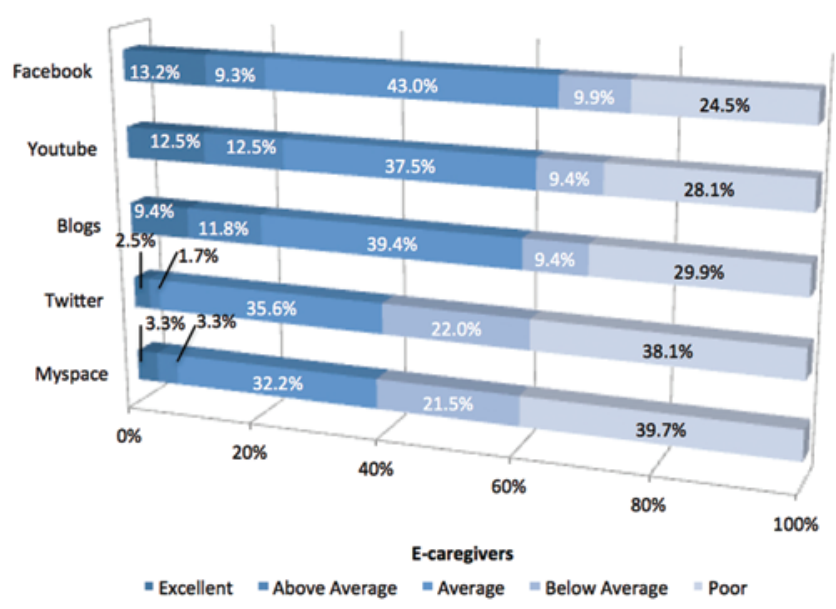

FIG. 6. Generally, social media were rated "average" in providing social support. Facebook and YouTube were rated the highest followed closely by blogs. Twitter and Myspace were not preferred.
Internet use (75\% of all hydrocephalus caregivers). According to Fox, ${ }^{8} 59 \%$ of all American adults use the Internet to search for health care information. The elevated Internet use, both for personal and hydrocephalus-related purposes, is attributable to the society role of "caregiver," which not only increases personal Internet use, but also increases health-related Internet use $(70 \%$ of caregivers vs $59 \%$ of all adults in the general population).

While technology and Internet use were prevalent, lower income, minority race, and lower educational achievement consistently correlated with limited access. Research in medical informatics has long correlated socioeconomic factors with access to technology. ${ }^{2,18,39,41}$ Data from the Pew Internet and American Life Project have profiled Internet users as primarily Caucasian, higher economic strata, well educated, and young (ages 18-49 years).$^{8,18,41}$ Our findings are congruent with these except that we found no correlation with age. This is attributed to the fact that nearly all caregivers were within the young age range.

These same socioeconomic factors were not only associated with limiting access to technology but also guided Internet behavior among e-caregivers (Fig. 3). Use of the Internet for hydrocephalus information was consistently lower among e-caregivers who were African American and/or had lower income and lower education status, even though all had access to the Internet. Pew survey results found the same socioeconomic factors as predictors of seeking health care information online. ${ }^{8}$

Trustworthiness and utility of the Internet are concerns in health care technology. ${ }^{13,40}$ Studies have recognized that information found on the Internet can be inaccurate, ${ }^{3}$ difficult to understand,,${ }^{3,40}$ and even useless. ${ }^{35,37}$ Interestingly, as early as 2001, hydrocephalus was recognized as having the highest-quality online information among all neurosurgery topics. ${ }^{7}$ In the current study, most e-caregivers of patients with hydrocephalus found the Internet to be helpful (Fig. 1A); however, they remain skeptical of the trustworthiness of Internet information (Fig. 1C). Because of this slight distrust, e-caregivers expressed interest in Internet resources recommended by their neurosurgeon. In responding to the HINTS, patients reported that they trusted their physicians most, but the Internet was their second most trusted source of information. ${ }^{22}$ Most caregivers and patients prefer obtaining medical information from the physician; however, in reality, most are actually seeking information on the Internet first. ${ }^{13}$ Because patients and their caregivers are initially turning to the Internet, neurosurgeons should provide vetted website recommendations to ensure that valid and reliable information sources are being used.

Smartphone mobile Internet access is important because adults who access the Internet through a mobile connection are more engaged in Internet and technology utilization. Mobile access acts as an accelerant to overall individual online activity. ${ }^{15} \mathrm{~A}$ smartphone was the second most common method of accessing the Internet, trailing only personal computers, for caregivers of hydrocephalic patients.

Our data reveal significant differences in smartphone ownership based on race, income, and level of education. 
While a Pew survey reports the same disparities correlating with income and education, they found that smartphones are breaking down the racial digital divide. African Americans and Latinos were more likely than Caucasians to own and use smartphones to access the Internet according to a Pew survey and an HIV disease-specific study. ${ }^{16,36}$ With the expanding mobile Internet and its potential for breaking down socioeconomic barriers, attention should be paid to these devices as an important access point for e-caregivers now and in the future.

\section{Social Media}

Among the $91.7 \%$ of caregivers of hydrocephalic patients who use the Internet, $95.1 \%$ access at least one form of social media. In comparison, $79 \%$ of American adults used the Internet and $65 \%$ of these users accessed social media in 2011..$^{30}$ Social media use has become increasingly prevalent, doubling between 2008 and 2010.12 Trailing only e-mail and search engines, social media tools are the third most popular tools on the Internet. ${ }^{30}$ With this trend in growth and popularity, social media use among e-caregivers can be expected to remain nearly universal.

In Table 1 the specific social media included in this study are listed along with a description or mission statement from their own websites. The general theme of the descriptions is that each brand of social media acts as a platform to share user-generated content. Each by definition is a fluid stream of information. All are customizable such that a generator or consumer of information can create any themed online world or community. The capability for multiple individuals to pool thoughts and information creates an environment that fosters a collective intelligence. As Hesse et al. ${ }^{14}$ describe it, the premise behind collective intelligence is not new; in fact, it is the underlying rationale for libraries or even for publishing in scientific journals. What is unique about social media is that these communication pathways between sources are now more accessible and fluid. Therefore, social media provide an interactive platform for caregivers to gain a shared knowledge from what they have learned through interactions with physicians, reading, and personal medical experiences.

In previous studies, the most reliable predictor of social media use was age, ${ }^{5,28,30}$ however, no correlation was found in this study. Traditionally, social media use was limited to young Internet users, ${ }^{5}$ but since 2008, adoption of social media by all age groups has increased, and the most pronounced growth has been among adults older than 35 years. ${ }^{12,30}$ Social media are still most frequently used by the 23-35 and 36-49 year age groups. ${ }^{12}$ Nearly every hydrocephalus caregiver was within this age range of maximum utilization (the average age of participants was $36.7 \pm 10.4$ years), so age was not found to correlate with use.

As discussed above, people of minority race, lower income, and lower educational level have decreased access to technology and the Internet. ${ }^{8,20,26,28,34,36}$ However, social media are reported to have broken down some of these socioeconomic disparities, as their use is not restricted by race, ethnicity, income, education level, or geographic location. ${ }^{5,28,30}$ The current study also found no correlation between social media use and race, income, or geographic location. In a reversal of the usual disparity, less-educated caregivers were more likely than highly educated caregivers to use social media $(99.1 \%$ vs $92.1 \%$, respectively). However, the fact that over $90 \%$ of those surveyed in either group were utilizing social media speaks to the astounding pervasive power of social media in our modern society. Interestingly, unlike the situation with hydrocephalus-related Internet use, race, income, and education level did not correlate with hydrocephalus-related social media use. Thus, national movements to broaden access to broadband Internet and the natural trends of social media growth should further break down the digital divide and allow outreach into target populations for Internet health care education and support.

The only patient factor that correlated with hydrocephalus-related social media use was experience with shunt failure; inexperienced caregivers were more likely than experienced caregivers to use social media for hydrocephalus-related purposes. This finding suggests that caregivers who have experienced more shunt failures depend on personal experience as their guide rather than seeking further information online. Previous publications from our group indicate that this experience-driven attitude toward shunt failure may not be as accurate as previously believed. ${ }^{32}$ It is likely that neurosurgeon-recommended social media and Internet sources could be used in a more deliberate way to further educate and direct this group of experienced e-caregivers.

\section{Internet Platforms and Topics of Interest}

Wikipedia and social media sites are relatively new to the Internet and are a component of Web 2.0-a more interactive, social internet that allows greater user freedom and interconnectivity. ${ }^{19}$ When e-caregivers of patients with hydrocephalus seek online information, they indicate a preference for information sites such as the Hydrocephalus Association website or Wikipedia over all other media (Fig. 4). This is consistent with findings from the HINTS indicating that patients preferred official information websites (such as that of a cancer organization) because they are considered more credible. ${ }^{22}$ One would expect that hospital websites would be considered a reliable location for credible information; however, hospital websites are not heavily used. ${ }^{21}$

Over half of e-caregivers enjoyed using social media and YouTube to learn about hydrocephalus. As a whole, e-caregivers were less interested in using blogs, podcasts, or RSS. Preference for these platforms reversed some of the socioeconomic trends in technology and Internet use. Level of education was the most important factor predicting the degree of preference for various platforms. Caregivers with lower levels of education preferred information sites and social media more than higher-educated caregivers. According to the findings of this study, information sites may act as the primary source of Internet hydrocephalus education for most caregivers, but social media and educational videos may be a more effective platform for educating caregivers in minority socioeconomic strata.

Since 2002, the top-ranked health searches on the 
Internet were related to specific diseases $(66 \%$ of Internet users) and information about a medical treatment or procedure (56\% of Internet users). ${ }^{8}$ Studies indicate that caregivers and patients are more interested in diseasespecific inquiries than in searches on their physicians or hospitals..$^{8,35}$ E-caregivers of hydrocephalic patients indicated that they are most interested in learning about shunt failure, general hydrocephalus information, and potential new therapies (Fig. 5). In addition, over half of respondents expressed interest in online support groups.

Of the specific social media that were involved in the survey, Facebook and YouTube were the most preferred for personal use, which is not surprising because Pew surveys indicate that Facebook is dominant in the world of social media. ${ }^{12}$ As with personal social media use, Facebook and YouTube were the two most preferred media for hydrocephalus-related use, and these two platforms have the greatest potential influence for hydrocephalus outreach and education. Fox ${ }^{10}$ reported that $25 \%$ of Internet users have watched an online video about health or medical issues. In the current study, $78.0 \%$ of e-caregivers were likely to watch educational videos on YouTube, which exceeded any interest in downloading and listening to podcasts. YouTube offers a unique interface for physicians to communicate with caregivers and patients in short videos, allowing opportunities for multimodality education. It is also an interface that can be used by caregivers and patients to share their experiences with others.

\section{Support Groups}

Social media can be more than a source of health information; they can be a source of emotional encouragement. ${ }^{10}$ Hampton et al. ${ }^{12}$ studied different types of social support including emotional, companionship, and tangible support, finding that Internet users had more social support than nonusers, and of these, Facebook provided the greatest social support. Fox ${ }^{9}$ found that input from peers was more important for emotional support than professional input. Especially in rare conditions, when patients have a health concern, they are more likely than any other group to turn to their online peer group for answers. Caregivers of patients with rare conditions confide in others going through similar experiences when they would not confide in anyone else. Through the relationships formed in social media, caregivers are able to join collectively, often without ever meeting in person.

Just over half of e-caregivers of patients with hydrocephalus expressed interest in using the Internet to find support groups, but currently only $28.6 \%$ used the Internet to find online support groups, and $34.8 \%$ communicated with others who have shared similar experiences. This is still a large portion of e-caregivers who are turning to online resources for their social support.

As a point of reference, in the 2007 HINTS, $4.6 \%$ of Internet users with cancer participated in online support groups. ${ }^{5}$ According to a 2011 Pew survey, $18 \%$ of Internet users go online to find others with similar health concerns (23\% of those with chronic or rare diseases). ${ }^{9,10}$ In 2011, caregivers used online support groups more than any other subgroup of American adults, with $26 \%$ of caregivers with Internet access using it to connect to others in a similar situation. ${ }^{9}$ Therefore, the $28.6 \%$ of ecaregivers in our study group matches national trends of other caregivers closely.

While YouTube may not naturally be thought of as a platform for social support, the video interface is an important way for caregivers and patients to share experiences. This medium provides an opportunity for caregivers to tell stories, share testimonials, and offer support. ${ }^{4}$

\section{Limitations and Future Investigation}

This study was performed at a single site. While the study was designed so that the sample represented the patient population served at Children's of Alabama, readers may extrapolate our findings to other institutions and populations. For this purpose, the 2010 US Census provides that following data: Alabama's population is 4.8 million and consists of the following groups: 65\% Caucasian, 26\% African American, 4\% Hispanic, 1\% Asian, and $4 \%$ other race or ethnicity. Nearly all pediatric neurosurgical care for the state of Alabama is performed at Children's of Alabama.

This survey was only performed with English-speaking participants, which reduced the number of Hispanic participants. This is an important subgroup that is not included in this study. According to Pew data, ${ }^{8}$ Hispanics face the same socioeconomic disparities regarding access and use of technology as other minority populations. As in the African American community, smartphones and social media are breaking down this barrier. ${ }^{36}$ A future area of investigation should be technology access, Internet use and preferences, and search terms for non-English speaking caregivers.

The technology industry is the fastest progressing field in business. By the time this report is published, habits and trends of technology users are likely to have shifted. In 1998 Maugans et al. ${ }^{31}$ found AOL Netfind and Excite to be the most useful search engines for information regarding pediatric neurosurgical diagnoses. Presciently, they noted that while this was true at that time, "[this] will almost certainly change in this rapidly evolving arena." Currently, neither search engine is among the top 4 used. Similarly, the popularity of various social media sites changes over time. For example, Facebook is currently the most popular site, Twitter has demonstrated the greatest recent growth, and Myspace was the most visited social media site from 2005-2008 but more recently has added relatively few new users. ${ }^{12}$ The specific sites that hydrocephalus caregivers prefer and the way they use these sites may change over time, but these caregivers have displayed an interest in using social media in dealing with hydrocephalus, and there is no reason to believe that this would wane over time.

We have profiled how caregivers are using technology, the Internet, and social media and established that these are omnipresent forces in their health care experience. This study did not establish whether e-caregivers consume or use health care in a different way from those who do not use these resources. There has also been no attempt to establish whether the use of this information positively or negatively influences any outcomes. This would be an important upcoming investigation. With 
this information, health care utilization of technology resources could be tailored to those that positively affect outcomes.

\section{Conclusions}

Technology hardware, the Internet, and social media are prevalent in hydrocephalus caregivers' personal and health care lives. Socioeconomic factors including race, income, and level of education reveal a disparity in access to some of these resources, but all groups have relatively high use, and social media are beginning to break down this digital divide. Approaching the Internet with an appropriate skepticism, caregivers find the Internet helpful in learning about hydrocephalus. When they go online, they are most interested in shunt failure, general hydrocephalus information, and potential new therapies; however, over half desire social support. They generally prefer information websites like Wikipedia or the Hydrocephalus Association website, but social media, primarily Facebook and YouTube, occupy an increasingly important role in their lives. Neurosurgeons and hospital systems should be prepared to provide their patients with recommendations for credible Internet sources, be willing to discuss information obtained from the Internet, and even consider collaboration to produce high-quality social media content for patient education and caregiver support. The result of this adoption of social media is a new and powerful collective intelligence that spans socioeconomic and racial boundaries, with the potential to improve outcomes in all children with neurosurgical disease.

\section{Disclosure}

The authors report no conflict of interest concerning the materials or methods used in this study or the findings specified in this paper.

Author contributions to the study and manuscript preparation include the following. Conception and design: Naftel, Shannon, Wellons, Johnston. Acquisition of data: Safiano, Shannon. Analysis and interpretation of data: Naftel, Safiano, Falola. Drafting the article: Naftel, Safiano. Critically revising the article: all authors. Reviewed submitted version of manuscript: all authors. Approved the final version of the manuscript on behalf of all authors: Naftel. Statistical analysis: Falola. Administrative/technical/material support: Shannon, Wellons, Johnston. Study supervision: Wellons, Johnston.

\section{References}

1. Acakpo-Satchivi L, Shannon CN, Tubbs RS, Wellons JC III, Blount JP, Iskandar BJ, et al: Death in shunted hydrocephalic children: a follow-up study. Childs Nerv Syst 24:197-201, 2008

2. Bansil P, Keenan NL, Zlot AI, Gilliland JC: Health-related information on the Web: results from the HealthStyles Survey, 2002-2003. Prev Chronic Dis 3:A36, 2006

3. Berland GK, Elliott MN, Morales LS, Algazy JI, Kravitz RL, Broder MS, et al: Health information on the Internet: accessibility, quality, and readability in English and Spanish. JAMA 285:2612-2621, 2001

4. Chou WY, Hunt Y, Folkers A, Augustson E: Cancer survivorship in the age of YouTube and social media: a narrative analysis. J Med Internet Res 13:e7, 2011
5. Chou WY, Hunt YM, Beckjord EB, Moser RP, Hesse BW: Social media use in the United States: implications for health communication. J Med Internet Res 11:e48, 2009

6. Dhillon AS, Albersheim SG, Alsaad S, Pargass NS, Zupancic JA: Internet use and perceptions of information reliability by parents in a neonatal intensive care unit. J Perinatol 23:420424, 2003

7. Ellamushi H, Narenthiran G, Kitchen ND: Is current information available useful for patients and their families? Ann R Coll Surg Engl 83:292-294, 2001

8. Fox S: Health topics. Pew Internet and American Life Project. February 1, 2011 (http://www.pewinternet.org/Reports/ 2011/HealthTopics.aspx) [Accessed September 14, 2012]

9. Fox S: Peer-to-peer healthcare. Pew Internet and American Life Project. February 28, 2011 (http://pewinternet.org/ Reports/2011/P2PHealthcare.aspx) [Accessed September 14, 2012]

10. Fox S: Social life of health information. Pew Internet and American Life Project. June 11, 2009 (http://www.pewinter net.org/Reports/2009/8-The-Social-Life-of-Health-Informa tion.aspx) [Accessed September 14, 2012]

11. Fox S, Purcell K: Chronic disease and the internet. Pew Internet and American Life Project. March 24, 2010 (http:// www.pewinternet.org/Reports/2010/Chronic-Disease.aspx) [Accessed September 14, 2012]

12. Hampton K, Goulet LS, Rainie L, Purcell K: Social Networking Sites and Our Lives. Pew Internet and American Life Project. June 16, 2011 (http://www.pewinternet.org/Reports/ 2011/Technology-and-social-networks.aspx) [Accessed September 14, 2012]

13. Hesse BW, Nelson DE, Kreps GL, Croyle RT, Arora NK, Rimer BK, et al: Trust and sources of health information: the impact of the Internet and its implications for health care providers: findings from the first Health Information National Trends Survey. Arch Intern Med 165:2618-2624, 2005

14. Hesse BW, O'Connell M, Augustson EM, Chou WY, Shaikh AR, Rutten LJ: Realizing the promise of Web 2.0: engaging community intelligence. J Health Commun 16 (Suppl 1): $10-31,2011$

15. Horrigan J: The mobile difference. Pew Internet and American Life Project. March 25, 2009 (http://www.pewinternet. org/Reports/2009/5-The-Mobile-Difference--Typology.aspx) [Accessed September 14, 2012]

16. Horvath KJ, Danilenko GP, Williams ML, Simoni J, Amico KR, Oakes JM, et al: Technology use and reasons to participate in social networking health websites among people living with HIV in the US. AIDS Behav 16:900-910, 2012

17. Iskandar BJ, Tubbs S, Mapstone TB, Grabb PA, Bartolucci AA, Oakes WJ: Death in shunted hydrocephalic children in the 1990s. Pediatr Neurosurg 28:173-176, 1998

18. Jansen J: Use of the internet in higher-income households. Pew Internet and American Life Project. November 24, 2012 (http://pewinternet.org/Reports/2010/Better-off-house holds.aspx) [Accessed September 14, 2012]

19. Kamel Boulos MN, Wheeler S: The emerging Web 2.0 social software: an enabling suite of sociable technologies in health and health care education. Health Info Libr J 24:2-23, 2007

20. Khazaal Y, Chatton A, Cochand S, Hoch A, Khankarli MB, Khan R, et al: Internet use by patients with psychiatric disorders in search for general and medical informations. Psychiatr Q 79:301-309, 2008

21. Khoo K, Bolt P, Babl FE, Jury S, Goldman RD: Health information seeking by parents in the Internet age. J Paediatr Child Health 44:419-423, 2008

22. Kim K, Kwon N: Profile of e-patients: analysis of their cancer information-seeking from a national survey. J Health Commun 15:712-733, 2010

23. Kim R, Kelly PJ: Applications of the World Wide Web to neurosurgical practice. Neurosurgery 39:1169-1182, 1996 


\section{R. P. Naftel et al.}

24. Kim TY, Brown L, Stewart GM: Test characteristics of parent's visual analog scale score in predicting ventriculoperitoneal shunt malfunction in the pediatric emergency department. Pediatr Emerg Care 23:549-552, 2007

25. Kind $\mathrm{T}$ : The Internet as an adjunct for pediatric primary care. Curr Opin Pediatr 21:805-810, 2009

26. Koch-Weser S, Bradshaw YS, Gualtieri L, Gallagher SS: The Internet as a health information source: findings from the 2007 Health Information National Trends Survey and implications for health communication. J Health Commun 15 (Suppl 3):279-293, 2010

27. Komotar RJ, Zacharia BE, Mocco J, Ransom ER, Davis JP, Gasparis G, et al: Internet-based neuro-oncology patient recruitment. Neurosurgery 58:985-989, 2006

28. Kontos EZ, Emmons KM, Puleo E, Viswanath K: Communication inequalities and public health implications of adult social networking site use in the United States. J Health Commun 15 (Suppl 3):216-235, 2010

29. Likert R: A technique for the measurement of attitudes. Arch Psychol 22:1-55, 1932

30. Madden M, Zickuhr K: $65 \%$ of online adults use social networking sites. Pew Internet and American Life Project. August 26, 2011 (http://www.pewinternet.org/Reports/2011/ Social-Networking-Sites.aspx) [Accessed September 14, 2012]

31. Maugans TA, McComb JG, Levy ML: The internet as a pediatric neurosurgery information resource. Pediatr Neurosurg 28:186-190, 1998

32. Naftel RP, Tubergen E, Shannon CN, Gran KA, Vance EH, Oakes WJ, et al: Parental recognition of shunt failure: a prospective single-institution study. Clinical article. J Neurosurg Pediatr 9:363-371, 2012

33. Pareras LG, Martin-Rodriguez JG: Neurosurgery and the Internet: a critical analysis and a review of available resources. Neurosurgery 39:216-233, 1996

34. Seto E, Cafazzo JA, Rizo C, Bonert M, Fong E, Chan CT: Internet use by end-stage renal disease patients. Hemodial Int 11:328-332, 2007

35. Shah A, Kuo A, Zurakowski D, Waters PM: Use and satis- faction of the internet in obtaining information on brachial plexus birth palsies and its influence on decision-making. J Pediatr Orthop 26:781-784, 2006

36. Smith A: Smartphone adoption and usage. Pew Internet and American Life Project. July 11, 2011 (http://pewinternet.org/ Reports/2011/Smartphones.aspx) [Accessed September 14, 2012]

37. Stoevesandt D, Diez C: Is the Internet a useful and relevant source for health and health care information retrieval for German cardiothoracic patients? First results from a prospective survey among 255 patients at a German cardiothoracic surgical clinic. J Cardiothorac Surg 1:36, 2006

38. Tuffrey C, Finlay F: Use of the internet by parents of paediatric outpatients. Arch Dis Child 87:534-536, 2002

39. van Uden-Kraan CF, Drossaert CH, Taal E, Smit WM, Moens HJ, Siesling S, et al: Health-related Internet use by patients with somatic diseases: frequency of use and characteristics of users. Inform Health Soc Care 34:18-29, 2009

40. Wainstein BK, Sterling-Levis K, Baker SA, Taitz J, Brydon M: Use of the Internet by parents of paediatric patients. J Paediatr Child Health 42:528-532, 2006

41. Zickuhr K: Generations 2010. Pew Internet and American Life Project. December 16, 2010 (http://www.pewinternet. org/Reports/2010/Generations-2010.aspx) [Accessed September 14, 2012]

Manuscript submitted April 12, 2012.

Accepted September 13, 2012.

Current affiliation for Dr. Wellons: Department of Neurosurgery, Vanderbilt University Medical Center, Nashville, Tennessee.

Please include this information when citing this paper: published online October 23, 2012; DOI: 10.3171/2012.9.PEDS12208.

Address correspondence to: Robert P. Naftel, M.D., University of Alabama at Birmingham, Division of Neurosurgery, 51020 th Street South, FOT 1062, Birmingham, Alabama 35294-3410. email: naftel@uab.edu. 